03

\title{
Интенсификация теплообмена в нагреваемой пленке жидкости при воздействии внешних искусственных возмущений
}

\author{
(C) E.A. Чиннов ${ }^{1,2}$, И.А. Шарина ${ }^{1}$ \\ ${ }^{1}$ Институт теплофизики им. С.С. Кутателадзе СО РАН, Новосибирск, \\ Россия \\ ${ }^{2}$ Новосибирский государственный университет, Новосибирск, Россия \\ E-mail: chinnov@itp.nsc.ru
}

Поступило в Редакцию 4 июля 2018 г.

Выполнено исследование теплообмена в нагреваемой пленке дистиллированной воды при воздействии внешних искусственных возмущений с „наиболее опасной длиной волны“ и изменении числа Рейнольдса от 300 до 500. Показано, что при увеличении плотности теплового потока воздействие искусственных возмущений приводит к изменению ривулетно-волновой структуры течения, росту амплитуд волн и в конечном счете к интенсификации теплообмена.

DOI: 10.21883/PJTF.2018.21.46854.17449

Пленочные течения являются основой многих технологических процессов, в которых имеет место тепломассоперенос. Они используются в дистилляционных колоннах, градирнях, каталитических реакторах, абсорберах, системах охлаждения и термостабилизации [1-5]. В настоящее время продолжаются активные исследования пленочных течений жидкости и поиск способов интенсификации тепломассообмена. В работе [6] выполнено экспериментальное исследование теплообмена при течении пленки воды по вертикальной поверхности с нагревателем для чисел Рейнольдса от 1 до 45. Обнаружен рост локального коэффициента теплоотдачи при возрастании теплового потока в нижней части нагревателя в межструйной области. В [7] обнаружена интенсификация теплообмена в стекающей пленке воды при воздействии искусственных возмущений с „наиболее опасной длиной волны“ для числа Рейнольдса 250. В [8] экспериментально установлено, что в стекающей пленке жидкости вдоль тонкостенного нагревателя распространяющийся фронт 
повторного смачивания характеризуется ячеистой структурой с регулярными кипящими струями и межструйными зонами. В [9] теоретически показано, что на поверхности пленки конденсата развиваются естественные волны, обусловленные неустойчивостью течения, которые существенно интенсифицируют теплоперенос. В [10] выполнено исследование гидродинамики и теплообмена в стекающих пленках жидкости, представлена методика синхронного измерения температуры и скорости межфазной поверхности. Показано, что локальный мгновенный коэффициент теплоотдачи коррелирует с локальной мгновенной толщиной пленки жидкости, что приводит к значительной интенсификации теплообмена. В стекающих неизотермических пленках жидкости выделено два режима формирования струй [11]. При появлении структур в режиме $A$ в верхней части нагревателя наблюдались высокие градиенты температуры до $10-15 \mathrm{~K} / \mathrm{mm}$. На поверхности нагревателя реализовалось граничное условие, близкое к $T=$ const. При достижении пороговой плотности теплового потока в верхней части нагревателя на поверхности пленки появлялись значительные деформации, а течение разделялось на вертикальные струи. При малых числах Рейнольдса высокие термокапиллярные напряжения, направленные против течения, приводили к утолщению пленки в виде горизонтального вала [12]. $\mathrm{B}$ режиме $B$ формирование струйного течения происходило постепенно с ростом теплового потока и расстояния от верхней кромки нагревателя [11]. На поверхности нагревателя реализовалось граничное условие $q=$ const, где $q$ - плотность теплового потока, а градиенты температуры на поверхности пленки не превышали $1 \mathrm{~K} / \mathrm{mm}$. Под действием термокапиллярных сил, направленных от более горячих областей к холодным, происходил рост деформации поверхности пленки. Анализ внешних искусственных воздействий на волновую динамику и пульсации температуры в нагреваемых пленках жидкости важен для понимания механизмов интенсификации теплообмена и разрыва пленки. Установлено, что при создании внешних возмущений за счет системы расположенных в горизонтальную линию цилиндров одинакового диаметра, которая опускалась в пленку жидкости выше верхнего края нагревателя, происходило существенное изменение деформации на поверхности нагреваемой пленки [11]. В работе [13] определена „наиболее опасная длина волны“, при которой искусственные возмущения существенно изменяют расстояние между струями в неизотермической стекающей пленке жидкости. Показано, что для $\mathrm{Re}<40$ „наиболее опасная длина волны“" для пленки воды составляет 9.5-10 mm. В [14]

Письма в ЖТФ, 2018, том 44, вып. 21 
показано, что искусственные возмущения с этим же расстоянием между цилиндрами изменяют расстояние между струями до $\mathrm{Re}=500$.

Задачей настоящей работы является экспериментальное исследование влияния внешних возмущений с „наиболее опасной длиной волны“ на интенсивность теплоотдачи в нагреваемой пленке жидкости при различных значениях плотностей тепловых потоков для $\mathrm{Re}=300-500$ в условиях течения развитых трехмерных синхронных волн по поверхности пленки воды вдоль нагревателя.

Экспериментальная установка представляла собой замкнутый циркуляционный контур, включающий резервуар с электронасосом, вертикально расположенный рабочий участок и фильтр. Рабочий участок включал несущую текстолитовую плиту с нагревателем, выполненным в виде медной пластины размером $100 \times 150 \mathrm{~mm}$, стабилизатор температуры в виде плоского металлического теплообменника с системой каналов, установленный в верхней части несущей плиты, и пленкоформирователь.

Эксперименты выполнялись с открытым в атмосферу рабочим участком. Дистиллированная вода с помощью насоса через фильтр подавалась в пленкоформирователь, состоявший из накопительной камеры, распределительного устройства и сопла с калиброванной плоской щелью, стекала под действием гравитации в виде тонкой пленки по поверхности рабочего участка, накапливалась в резервуаре и с помощью насоса возвращалась в систему. Расстояние между соплом пленкоформирователя и передней кромкой нагревателя составляло $263 \mathrm{~mm}$.

На поверхности нагревателя было реализовано граничное условие $q=$ const. Температуры рабочей жидкости, поверхностей нагревателя и несущей плиты измерялись термопарами, имеющими индивидуальную тарировку, с погрешностью $0.1^{\circ} \mathrm{C}$. Начальная температура рабочей жидкости $T_{0}$ поддерживалась равной $24^{\circ} \mathrm{C}$ с помощью термостата. Число Рейнольдса пленки воды определялось по формуле $\operatorname{Re}=\Gamma / \mu$, где $\Gamma$ - массовый расход жидкости на единицу ширины пленки, $\mu-$ коэффициент динамической вязкости жидкости. Расход жидкости измерялся системой поплавковых ротаметров с погрешностью не более $1.5 \%$. Средний коэффициент теплоотдачи рассчитывался по зависимости $\alpha=q /\left(T_{w}-T_{0}\right)$, где $q-$ плотность теплового потока $\left[\mathrm{W} / \mathrm{cm}^{2}\right]$, $T_{w}$ - средняя температура поверхности нагревательного элемента $\left[{ }^{\circ} \mathrm{C}\right], T_{0}$ - начальная температура жидкости $\left[{ }^{\circ} \mathrm{C}\right]$. Средняя температура поверхности $T_{w}$ определялась по показаниям трех термопар, установленных по центру нагревателя вдоль вертикальной линии. Плотность

Письма в ЖТФ, 2018, том 44, вып. 21 


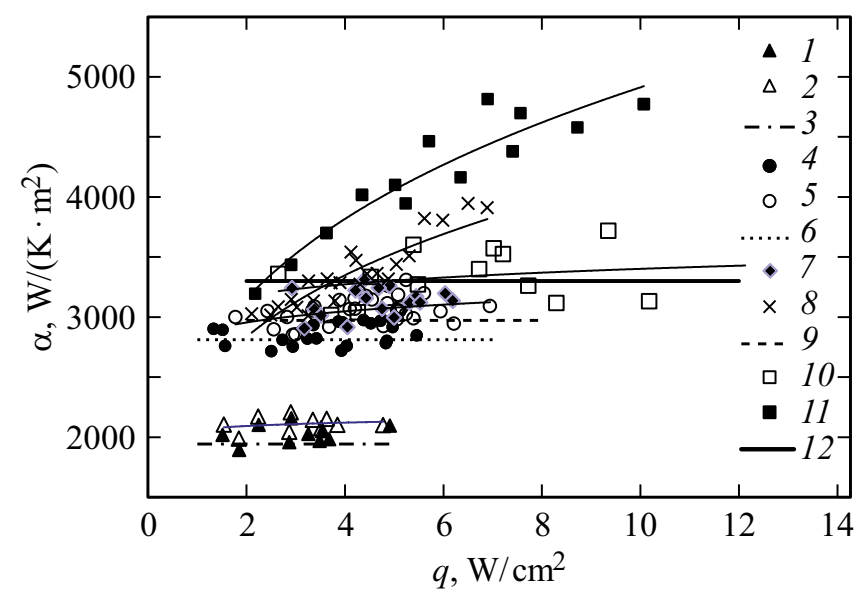

Рис. 1. Зависимость среднего коэффициента теплоотдачи от плотности теплового потока для $\operatorname{Re}=110(1-3), 300(4-6), 390(7-9), 500(10-12) .1,4,7$, 10 - невозмущенная пленка, 2, 5, 8, 11 - возмущенная пленка, 3, 6, 9, 12 расчет по формуле Нуссельта [16].

теплового потока изменялась в диапазоне $1-10 \mathrm{~W} / \mathrm{cm}^{2}$ и измерялась с погрешностью не более 7\%. Для внесения в поток возмущений использовалась система параллельно расположенных в линию с шагом $l_{w}=10 \mathrm{~mm}$ („наиболее опасная длина волны“) цилиндров диаметром $d_{w}=3 \mathrm{~mm}$. Мгновенное поле толщины и волновые характеристики изотермической пленки жидкости определялись с помощью флуоресцентного метода. Для возбуждения флуорофора использовался лазер, длина волны которого составляла $0.532 \mu \mathrm{m}$, непрерывно освещавший площадку размером $120 \times 120 \mathrm{~mm}$. Свет, отражаемый люминофором, регистрировался цифровой камерой, перед которой был установлен красный фильтр для отсечения отраженного света лазера. Подробное описание установки и методики измерений содержится в [15].

Из рис. 1 видно, что искусственные стационарные возмущения c „наиболее опасной длиной волны“ по мере увеличения плотности теплового потока приводят к увеличению коэффициента теплоотдачи при изменении числа Рейнольдса от 300 до 500 по сравнению со значениями, полученными для невозмущенной пленки жидкости и при расчете по теории Нуссельта [16]. Степень интенсификации теплообме-

Письма в ЖТФ, 2018, том 44, вып. 21 


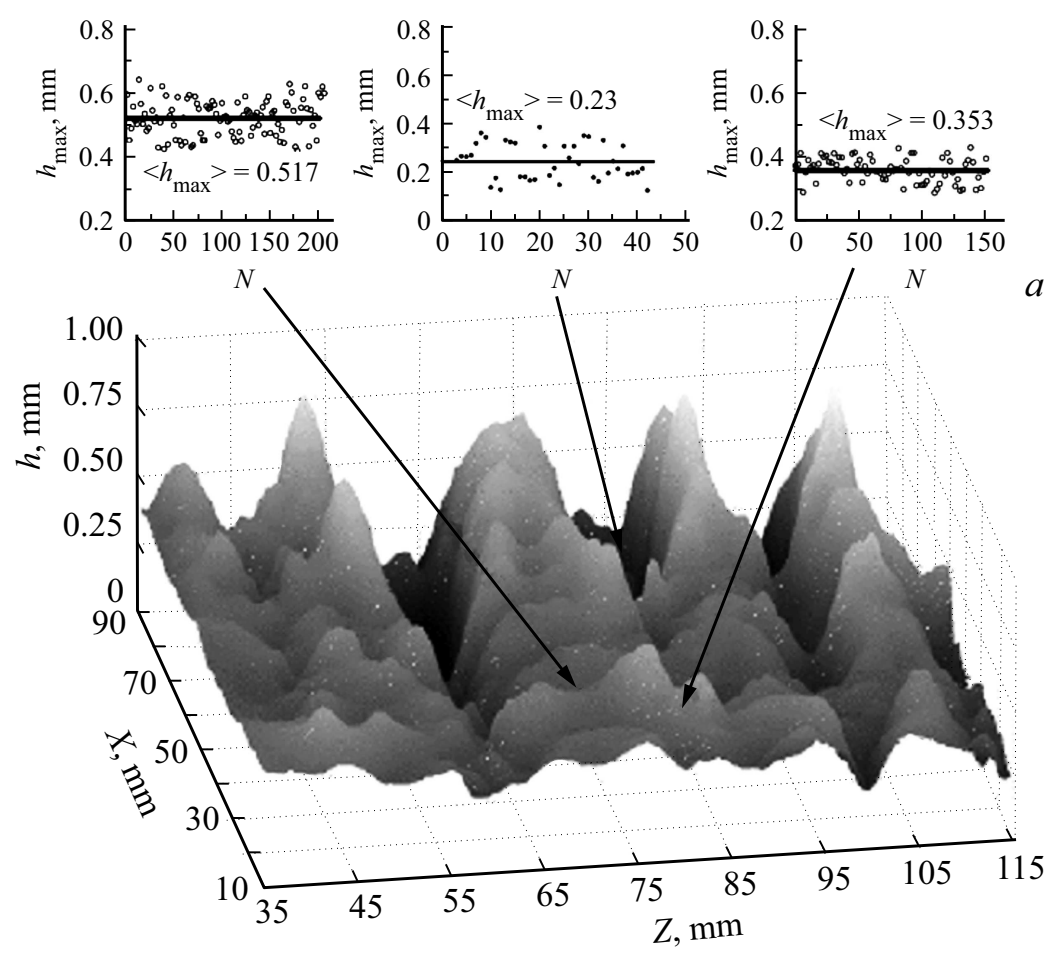

Рис. 2. Мгновенные распределения толщины пленки и амплитуды трехмерных волн на поверхности струй и в межструйной области невозмущенной пленки (a) и пленки с искусственным возмущением $(b)$ для $\operatorname{Re}=300, q=6.0 \mathrm{~W} / \mathrm{cm}^{2}$.

на (относительное увеличение коэффициента теплоотдачи) возрастает с увеличением числа Рейнольдса пленки. Так, при $\mathrm{Re}=300$ она составляет $13 \%$, при $\operatorname{Re}=390-30 \%$, а при $\mathrm{Re}=500$ достигает $40 \%$.

При числах $\operatorname{Re}=50-150$ искусственные стационарные возмущения с теми же параметрами не оказывают дополнительного влияния на теплообмен, так как структуры типа $A$, формируясь у верхней кромки нагревателя [15], уже создали возмущения, близкие по характеристикам к искусственным. Возмущения, развивающиеся на структурах $A$, приводят к интенсификации теплообмена по сравнению с расчетом Нуссельта $(\operatorname{Re}=110$, рис. 1$)$. В этом случае дополнительные возму- 


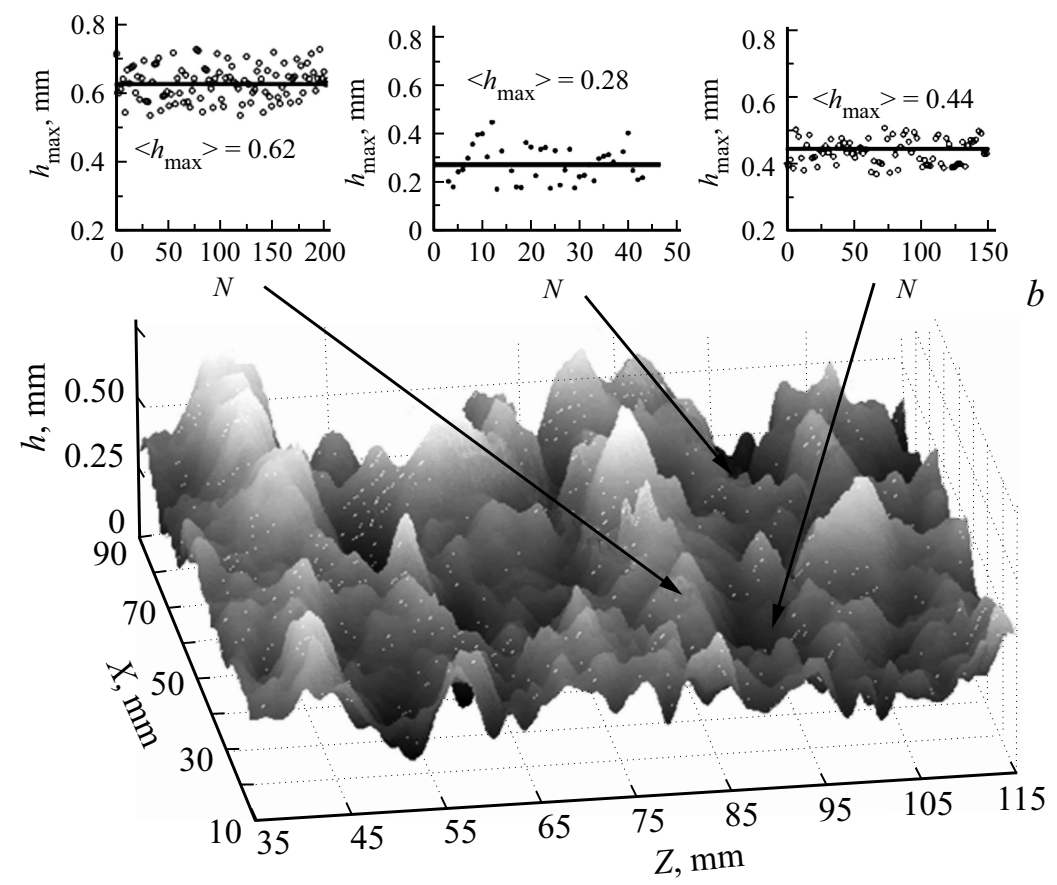

Рис. 2 (продолжение).

щения не изменяют структуру течения и не влияют на теплообмен. При $\mathrm{Re}=300-500$ формировались струи в режиме $B$, а по их гребням распространялись трехмерные волны. Воздействие искусственных возмущений существенно изменяло ривулетную и волновую структуру течения, что проявлялось в уменьшении расстояния между струями, увеличении амплитуд волн, увеличении толщины пленки жидкости в межструйной области, особенно в нижней части нагревателя.

Приведенные на рис. 2 мгновенные распределения толщины пленки $h$ в зависимости от координат $X$ и $Z$ вдоль и поперек течения пленки соответственно показывают выравнивание толщины пленки при воздействии внешних возмущений. За счет механического разрушения более крупных волн в верхней части нагревателя нарушалась структура синхронных волн. Мелкие волны, несущие на гребне холодную жидкость,

Письма в ЖТФ, 2018, том 44, вып. 21 
при движении вдоль нагревателя более равномерно распределялись по поверхности пленки, не позволяя образовываться значительным градиентам температуры (выравнивая температуру пленки), подавляя термокапиллярные силы и, следовательно, выравнивая толщину.

Увеличение средней амплитуды трехмерных волн $\left\langle h_{\max }\right\rangle$ (горизонтальные линии на рис. 2) при воздействии искусственных возмущений с „наиболее опасной длиной волны“ достигало в верхней части нагревателя в струях $20 \%$, в межструйной области - $25 \%$, в нижней части нагревателя в межструйной области - 20\%. Амплитуды определялись по максимальному значению толщины пленки на гребне волн для разного количества измерений $N$ в областях, указанных стрелками на рис. 2.

Таким образом, обнаружено, что в диапазоне чисел Рейнольдса от 300 до 500 наблюдается рост интенсивности теплообмена в нагреваемой пленке жидкости при воздействии искусственных возмущений с „наиболее опасной длиной волны“ до 40\%. Установлено, что искусственные возмущения изменяют струйную и волновую структуру пленки, увеличивая толщину пленки в межструйной области и амплитуду трехмерных волн, что является основным фактором, приводящим к повышению интенсивности теплообмена. Факт повышения интенсивности теплообмена и устойчивости пленки к разрыву при воздействии возмущений является важным, так как указывает на способ интенсификации теплообмена, что может быть использовано в различных промышленных технологиях.

Исследование выполнено за счет гранта Российского научного фонда (соглашение № 18-19-00407).

\section{Список литературы}

[1] Павленко A.H., Li X., Li H., Gao X., Володин O.A., Суртаев A.C., Сердюков В.С. // Письма в ЖТФ. 2015. Т. 41. В. 16. С. 21-28.

[2] Pecherkin N.I., Pavlenko A.N., Volodin O.A. // Int. J. Heat Mass Transfer. 2015. V. 90. P. $149-158$.

[3] Pecherkin N.I., Pavlenko A.N., Volodin O.A. // Heat Transfer Eng. 2016. V. 37. P. 257-268.

[4] Pavlenko A.N., Volodin O.A., Surtaev A.S. // Appl. Thermal Eng. 2017. V. 114. P. 1265-1274.

[5] Chernyavskii A.N., Pavlenko A.N. // Int. J. Heat Mass Transfer. 2017. V. 105. P. 648-654. 
[6] Чиннов Е.А., Кабов О.А. // ТВТ. 2004. Т. 42. В. 2. С. 269-278.

[7] Чиннов Е.А. // Письма в ЖТФ. 2008. Т. 34. В. 19. С. 27-33.

[8] Павленко А.Н., Суртаев А.С., Цой А.Н., Стародубцева И.П., Сердюков В.С. // ТВТ. 2014. Т. 52. В. 6. С. 886-894.

[9] Актершев С.П., Алексеенко С.В. // ТВТ. 2014. Т. 52. В. 1. С. 84-92.

[10] Charogiannis A., Zadrazil I., Markides C.N. // Int. J. Heat Mass. Transfer. 2016. V. 97. P. 589-595.

[11] Чиннов Е.А., Кабов О.А. // ПМТФ. 2003. Т. 44. № 5. С. 128-137.

[12] Kabov O.A. // Heat Transfer Research. 1996. V. 27. P. 221-226.

[13] Чиннов E.A. // ТВТ. 2009. Т. 47. В. 1. C. 68-74.

[14] Чиннов Е.A., Абдуракипов С.С. // ТВТ. 2014. Т. 52. В. 2. С. 246-251.

[15] Chinnov E.A. // Int. J. Heat Mass Transfer. 2017. V. 108. P. 2053-2059.

[16] Nusselt W. // Z. VDI. 1923. Bd. 67. N 9. P. 206-210. 